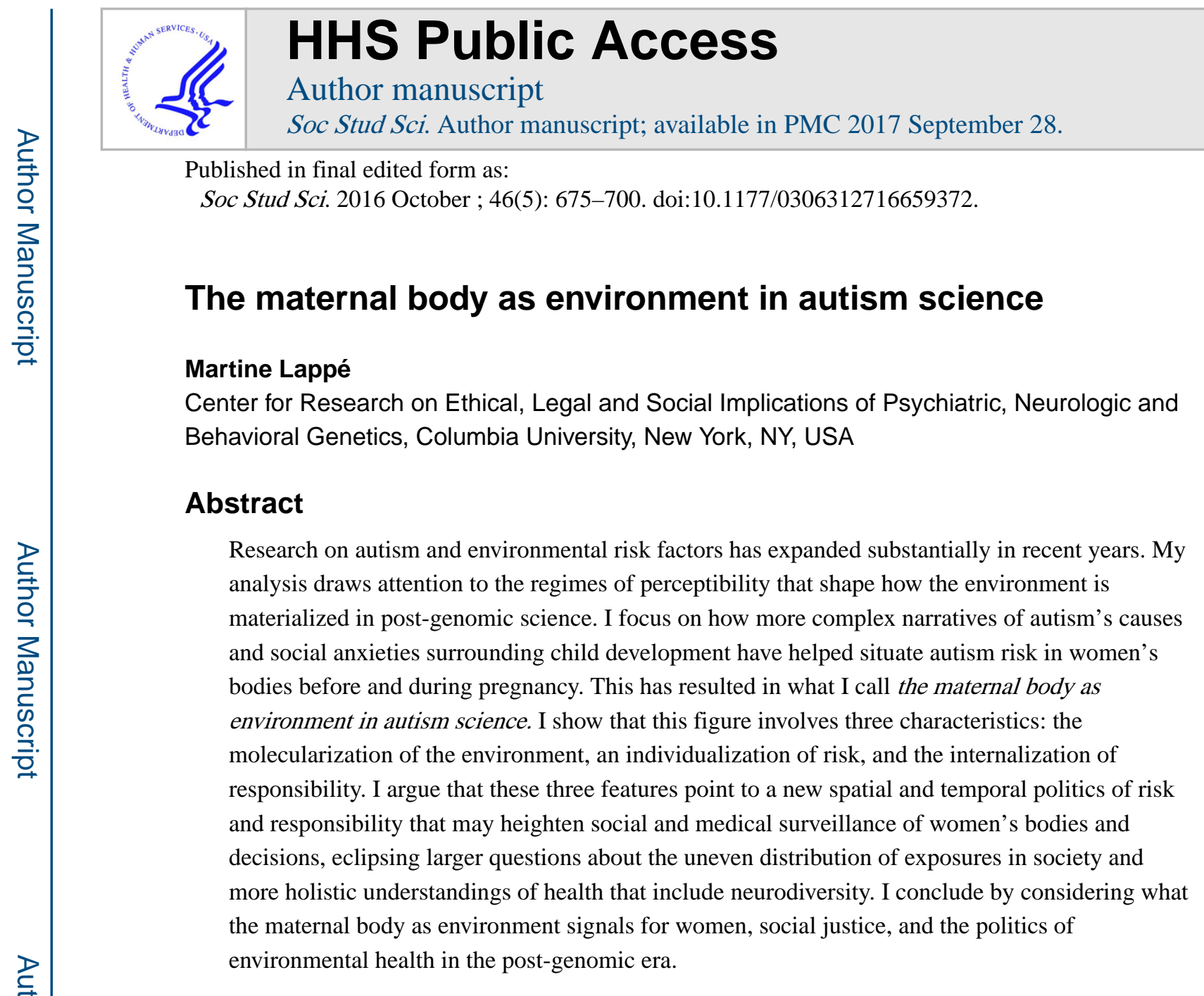

\title{
Keywords
}

autism; environment; health; maternal body; post-genomics; risk

What is new in risk culture is not the centrality of care to maternal citizenship, but the scope and complexity of that responsibility ... and the reach and precision of the sciences on which demands of mothers are founded.

(Wolf, 2011: 67).

\section{A picture worth a thousand words}

The illustration (Figure 1) depicts the mother-child dyad in vibrant tangles of red, orange, black, green, and magenta. The woman's body is made up of verdant plants, budding flowers, and swirling vines that wrap themselves around insects, dark pills, and bacteria. A caterpillar's body mimics the curve of a breast, a grasshopper the nape of the neck, and trumpet flowers frame a hollow space symbolizing the womb. In that space is a fleshy

Reprints and permissions: sagepub.co.uk/journalsPermissions.nav

Correspondence: Martine Lappé, Center for Research on Ethical, Legal and Social Implications of Psychiatric, Neurologic and Behavioral Genetics, Columbia University Medical Center, Unit 122, New York State Psychiatric Institute, 1051 Riverside Drive, New York, NY 10032, USA.md12161@ columbia.edu. 
human fetus, suspended as if weightless at the center of the image. The fetus is pale pink with small features that appear in stark contrast to the flowers and vines that make up its mother's body (Davis, 2012). ${ }^{1}$

While this image alone is striking, it is its relationship to longstanding constructions of maternal-fetal relations and contemporary understandings of autism spectrum disorders that make it particularly notable. In this article, I show that this illustration of a woman's body as a tangle of vines and microbiota with a fleshy fetus nestled within is emblematic of a larger shift in biological approaches to autism that began in the 1970s but did not become a concentrated area of autism science until the early 2000s. I argue that interest in the relationships between autism and environmental factors has positioned women's bodies as central to constructions of autism risk, while simultaneously reconfiguring the relationships that confer that risk. The result is a more pervasive yet precarious vision of children's development as a process that begins before birth and implicates women as mothers in more individual and molecular ways than the 'refrigerator mothers' of the past.

I document how the study of interactions between environmental risks, women's biology, and fetal brains is producing the maternal body as an environment of consequence for the future of autism, what I call the maternal body as environment in autism science. With this concept, I draw attention to how some approaches in contemporary autism science reinforce the idea of women's bodies as zones of potential health or harm for future children. While this focus has for years drawn attention to the womb, I argue that these logics are now positioning women's bodies themselves as environments of consequence for the future. What is noteworthy about the shift is how longstanding questions about the ways that women's experiences and exposures during pregnancy influence fetal development have converged with uncertainties surrounding autism at a critical moment in the life sciences, when understandings about the causes of health and disease are increasingly being troubled. I show that this convergence has rendered women's bodies critical sites for autism research, drawing social and scientific focus back to mothers, but in ways that are quite distinct from the past. The result is a temporal and spatial emphasis on autism risk that is explicitly articulated through the body. In this article, I examine how this figure came to be, its multiple manifestations in autism science, and what it signals for understandings of genetics, the environment, and maternal responsibilities in the post-genomic era.

The focus on the maternal body in autism science is by no means totalizing. ${ }^{2}$ Rather it is one part of a larger effort to locate autism in bodies and brains (Verhoeff, 2012). Facilitated by 'the somatization of autism' (Hollin and Pilnick, 2015: 279) and a move toward studying risks during earlier periods of development (Waggoner, 2015), these efforts produce research

\footnotetext{
${ }^{1}$ Dominant representations of autism have been criticized for their emphasis on white, middle- and upper-class children and families. The depiction of the fetus as white in this illustration is consistent with many representations of autism in science and popular culture. The rhetoric of autism's whiteness affects research priorities and influences inequalities in autism diagnosis and care (see Heilker, 2012).

${ }^{2}$ The idea that autism's origins lie in the womb has developed alongside research exploring the effect of environmental factors on sperm and how this, too, may influence offsprings' risk of autism (Malaspina et al., 2015; Reichenberg et al., 2006). Despite these investigations, to date environmental risks have largely been examined for their effects on the developing fetus in utero, placing attention on women's bodies as primary conduits for autism risk. The abundant attention paid to fetal development often displaces other notions of 'the environment', shaping how research is designed, the samples collected and analyzed, and their results understood (Daniels, 2006; Lappé, 2014).
} 
on autism and the environment - including toxins, chemicals, medications, and parent age as one agenda in a sea of studies attempting to identify evidence of autism before it is diagnosed. This anticipatory logic is particularly powerful when it comes to environmental factors, because they (unlike genetics) are assumed to be more easily modifiable and therefore hold particular promise in attempts to identify the source of autism's rising prevalence and potential avenues for prevention. The idea of autism as a biological problem is central to this assumption and forecloses more inclusive visions of the future advanced by neurodiversity, disability, and feminist advocates (Leiter, 2007; Murray, 2008; Silberman, 2015). My analysis here seeks to examine critically how the environment is conceptualized in autism research and the potential effects of that conceptualization for understandings of risk and responsibility today.

\section{Methods}

Data for this article are drawn from a multi-year, multi-sited ethnography that traced the emergence, practices, and consequences of autism environmental and gene-environment interaction science (Marcus, 1998). My analysis is based on a review of scientific, popular, and policy documents, including news media and peer-reviewed publications in major journals. It is also informed by my observations at scientific meetings, and interviews with autism scientists, autism advocates, and program officers at funding organizations in the United States from 2007 to 2012. My larger study included interviews with mothers of autistic children who were participants in a prospective cohort study exploring the environmental and genetic causes of autism during pregnancy and early childhood (MARBLES, 2016). While these interviews are not quoted, I mention them to provide a sense of the project from which this analysis of secondary resources is drawn and because these women's experiences informed my interest in how autism risk is being materialized in research practice (Lappé, 2014).

This article presents findings that emerged from my grounded theory analysis of this larger project (Charmaz, 2014; Clarke, 2005). By tracing environmental research on autism through the pages of peer-reviewed scientific publications and their accompanying media coverage, I found that conceptualizations of 'the environment' had the potential to reinforce and reconfigure maternal responsibilities by situating risk in and through women's bodies before and during pregnancy. I then identified two examples of contemporary autism research that illustrate distinct ways in which this is taking place. These examples are not meant to be exhaustive, nor do I survey the full range of research on autism, which is beyond the scope of this article. Rather, drawing on peer-reviewed scientific publications and media reports related to autism and the environment, I describe the scholarly and historical context through which the figure of the maternal body as environment emerged in autism science, two specific examples of its current instantiations in research practice, and its potential consequences in and beyond autism science.

\section{The maternal body as environment}

Murphy (2006) has developed the concept of 'regimes of perceptibility' to describe how 'a discipline or epistemological tradition perceives and does not perceive the world' (p. 10). In 
her work on the history of chemical exposures, she argues that regimes of perceptibility influence what can be seen, how knowledge is produced, and the material worlds that are made possible. In this article, I draw on this concept to consider how a convergence of questions about autism, causation, and health responsibilities helped produce the environment as a space of growing attention at the beginning of the post-genomic era. One quality of this era has been the flexibility of 'the environment' (Landecker and Panofsky, 2013; Shostak and Moinester, 2015).

Rather than being defined by a single discipline or tradition, the environment is being imagined as multiple, even while it continues to be thought about in relationship to genes (Shostak, 2013). By tracing the 'material yet relational ways things come to matter' (Murphy, 2006: 12) through the maternal body as environment in autism science, I attend to women's bodies as one site where autism risk is actively being produced and consider what this tells us about the intersections of risk and maternal responsibility in the post-genomic era.

The figure of the maternal body as environment in autism science builds on familiar tropes of the feminine as natural, the maternal body as a vessel, and of maternal-fetal symbiosis or conflict (Armstrong, 2003; Casper, 1998). Depictions of the maternal-fetal relationship have a long history in public health and biomedicine, with real consequences for women's lives (Kukla, 2010). Recent laws and public policies have helped temporally extend maternal responsibilities for children, positioning women as biologically and socially culpable for child wellbeing even before birth (Waggoner, 2015). This temporal and spatial emphasis on women's bodies as sites for children's wellbeing now includes the time before pregnancy as well, providing new valences on the periods of bodily experience that may matter for health (Lappé and Landecker, 2015a).

For example, it is now common for physicians and policymakers to reference 'preconception' as a pivotal period of time before pregnancy when women's experiences and decisions may influence the health of their potential children (Waggoner, 2015).

Epidemiological studies also cite the perinatal period as unique in shaping maternal and child wellbeing before, during, and shortly after pregnancy (Rabin, 2015), while epigenetic research has drawn attention to the cumulative effects that life experience may have for reproductive health (Barua and Junaid, 2015). These periods of focus reflect an extension of what originally motivated the rise of prenatal care and the surveillance of everything from anemia and vitamins to drug, alcohol and cigarette use during pregnancy, extending that surveillance into women's own bodies before pregnancy (Ginsburg and Rapp, 1991; Richardson, 2015).

Coupled with the contemporary medical and public health emphasis on women as prepregnant subjects (Centers for Disease Control and Prevention (CDC), 2016; Lee, 2016), there has been a simultaneous move in autism research to identify behavioral and biological risk factors for autism before it is diagnosed. Hollin and Pilnick (2015) argue that, 'within autism sciences, there has been a recent orientation towards infancy and the body ... that has produced a significantly altered disease construction of autism' (p. 280). Alongside this emphasis on infancy, researchers interested in the biological causes of autism have also 
come to think of fetal development as a unique window of vulnerability for the condition. In line with these trends in public health messaging and post-genomic science, I argue that this move has positioned the maternal body as central in where, when, and how autism risk is located and acted upon today.

\section{Three characteristics of the maternal body as environment in autism science}

The maternal body as environment - like autism itself - is multiple. It nevertheless involves three key characteristics that point to its particular spatial and temporal arrangement in the post-genomic era. These characteristics are the molecularization of the environment, an individualization of risk, and the internalization of responsibility. Together, these phenomena are pushing scientific attention back in developmental time and into the bodies of women as mothers and potential mothers. First, the maternal body as environment involves the molecularization of the environment. 'Molecularization' describes the processes through which life is increasingly visualized, operationalized, and intervened upon on the molecular level (Rose, 2007). Shostak (2013) argues that by focusing on molecularization we gain 'the opportunity to observe profound changes in how genes, environments, and human bodies are conceptualized and operationalized in scientific research' (p. 19). Her work analyzes the molecularization of the environmental health sciences, a phenomenon that informs the sciences I discuss below. Far from merely an example of geneticization (Lippman, 1991), the molecularization of the environment in autism science is constructing risk as a result of intimate and embodied relationships between life experiences, bodies, and developmental time (Shostak and Moinester, 2015).

In the sciences I describe, the processes of molecularization are informed by approaches in systems biology, genomics, immunology, and toxicology that increasingly have come to position disease as the result of multiple, interacting systems that rely on how genes are expressed, whether and when exposures occur, and the effects these processes have on development. Tracing these complex and contingent processes on the molecular level has led scientists to identify relationships between maternal bodies and fetal brains as central to questions of when, where, and how the environment might come to matter for autism. This means that far from something beyond the body, the environment is increasingly materialized as risky (or not) for children in relationship to women's own biology and embodied experiences. As others have argued (Richardson, 2015), this move to understand the effects of environmental risks in and through women's bodies has the potential to oversimplify complex life experiences, eclipse the political and economic conditions that structure who is vulnerable to environmental factors, and place the burden of responsibility on women as reproductive subjects. In the case of neurodevelopmental disorders, the molecularization of the environment is uniquely gendered, as it draws attention to women's bodies and lives as critical sites for the wellbeing of future children.

Second, the sciences I follow enable and are made possible by an ongoing individualization of risk characteristic of the post-genomic era. Since the completion of the major human genome projects, there has been a growing awareness that common traits and diseases are much more complex than previously imagined (Meloni, 2014). For autism, the impulse to individualize risks related to the condition is also closely tied to the condition's diagnostic 
imprecision. The autism spectrum has presented scientists with seemingly endless opportunities to pit and parse phenotypic features along biological lines in an effort to identify ever more specific subtypes and potential biomarkers along the broader spectrum (Navon, 2011). This is a trend that is likely to continue as autism becomes more genetically heterogeneous and awareness is raised about the diversity of experiences and symptoms that accompany the diagnosis (Navon and Eyal, 2016; Singh, 2015).

Importantly, this pitting and parsing also occurs along non-genetic lines - many of the scientists I interviewed used 'non-genetic' to define the environment when asked what they meant by the term. For example, in the study I observed, mothers of autistic children were enrolled during their subsequent pregnancies in an effort to identify whether differences in their experiences and exposures aligned with different rates of autism. This 'high-risk' cohort provided a resource for researchers to establish connections between women's experiences and autistic symptoms in their offspring, providing targets for future etiologic studies. This research has - in at least one case - resulted in the establishment of a new autism sub-type (Maternal Autoantibody-Related [MAR] autism) based on the presence of autoantibodies in mothers of autistic children (a finding that I discuss below). Thus, in what might be a striking development, the identification of non-genetic risk factors has been used to establish a sub-type of autism. This individualization of autism based on maternal biology signals an extension of attention from diagnosed individuals to their family members. This is particularly important to trace as it creates the potential for multiple autisms not only with regard to those diagnosed, but their kin as well (cf. Timmermans and Buchbinder, 2012).

Finally, the emergence of the maternal body as environment extends responsibilities for child wellbeing into women's bodies, further emphasizing women's responsibilities for the health of the population before and beyond pregnancy. This internalization of responsibility emphasizes women's biological culpability for child wellbeing - a theme evident in recent public health advisories related to alcohol consumption (CDC, 2016), Zika virus, (Lee, 2016), and CRISPR-Cas9 gene editing technology (Nature, 2016). The maternal body as environment in autism science builds on this larger cultural inclination by pushing concerns about children's development back in time and into the bodies and decisions of women as mothers and potential mothers. The materializations of the environment in contemporary autism science, therefore, suggest a temporal and material politics of risk that has received little attention with regard to autism, despite its rising relevance in biomedicine and the life sciences more generally (Adams et al., 2009; Murphy, 2013; Radin, 2013).

This spatial and temporal shift has at least two interesting consequences. First, by positioning autism risk in and through women's bodies, the sciences I describe simultaneously reconfigure the environment from something historically seen as external to the body to something constituted through women's bodies before and during pregnancy. This more contingent understanding of environmental risk has the potential to emphasize both collective exposures and individual biology, depending in part on the mechanisms hypothesized to lead to autism. Second, locating risk in women's bodies matters for experiences of motherhood and understandings of development that extend beyond autism as well. The material production of environmental risk in and through women's bodies - what I am calling the maternal body as environment - is therefore much more than metaphor: this 
figure is helping organize how we understand and act toward health and the sites we imbue with social and scientific importance.

\section{Technoscience and women's responsibilities for child health}

The regimes of perceptibility that have given rise to the maternal body as environment in autism science also contribute to its relevance as an object of biomedical and public attention, even as other causal narratives continue to circulate. These material connections between scientific objects and social experiences matter in tracing the emergence of this figure and its connections to enduring expectations of women in society. Feminist scholars have shown that responsibilities for fetal and child wellbeing are disproportionately placed on women as mothers and potential mothers (Almeling and Waggoner, 2013; Armstrong, 2003; Blum, 1999; Mackendrick, 2014; Waggoner, 2013). These burdens exist both within and beyond science, as social policies and health campaigns have been shown to influence experiences of consumption (Mackendrick, 2014; Szasz, 2007), risk related to environmental harms (Washburn, 2014), and women's culpability for fetal wellbeing (Kukla, 2010). These policies and practices implicate women by positioning their bodies and behaviors as sites of heightened scrutiny, amplifying cultures of mother blame (Blum, 2015; Singh, 2004).

The concepts of total motherhood (Wolf, 2011), intensive mothering (Hays, 1996), scientific motherhood (Apple, 2006), and medicalized motherhood (Litt, 2000), describe how women are further implored to channel care work into not only preventing illness but also optimizing health for children and potential children (Adams et al., 2009; Waggoner, 2013). The emergence of the maternal body as a site of growing attention in autism science is thus in line with extensions of women's responsibilities for care across the life course (Blum, 2015; Lappé and Landecker, 2015a; Waggoner, 2013; Wolf, 2011). Efforts to expand responsibility for children's wellbeing earlier in developmental time reflect what Waggoner (2013) has called a contemporary ethic of 'anticipatory motherhood', as well as a general sense of anticipation that increasingly accompanies risk discourse (Adams et al., 2009; Friese, 2013; Lappé, 2014).

Waggoner (2015) argues that these forms of surveillance now extend to all women, whether pregnant or not. In this way, the ethic of anticipatory motherhood assumes and supersedes pregnancy, becoming an orientation that positions women's bodies and decisions primarily as resources for others. Feminist science studies scholars have observed that this focus on the womb and women's bodies as zones of potential health or harm for fetal subjects remains central in post-genomic research (Richardson, 2015). Despite more complex models of causality, prenatal and early post-natal development have become sites of more intensive research attention over the past decade (Lappé and Landecker, 2015a).

Richardson (2015) documents the effects that this concentration has had in research on the epigenetics of maternal effects. She argues that this science positions the maternal body as a vector, 'at once a background element, a medium for the fetus. Yet it is also a "critical" developmental context in which environmental exposures are amplified, cues are transmitted, and genes are programmed' (p. 225). Richardson finds that as environments are channeled into molecular information, the maternal body becomes an intensified site of 
biological attention, producing 'conduit-like rather than strictly cause-effect, directional rather than distinctly determinative, and relational rather than cleanly linear' forms of causality mediated in and through women's bodies (p. 221). The degree to which today's more nuanced causal relationships remain located in and through women's bodies requires ongoing attention, as the social and public health pressures placed on women during pregnancy also extend to their responsibilities as parents.

While the mother-child dyad has received significant attention since autism was first named in 1943, multiple scholars have pointed out that expectations of 'good' mothering continue to produce childhood difference as a highly stigmatized experience that leaves many mothers feeling socially and biologically culpable for their children's diagnoses (Landsman, 2009; Rapp, 1999). The blaming of mothers for childhood disability has been written about in relationship to autism (Sousa, 2011; Silverman, 2011), attention deficit disorders (Blum, 2015; Singh, 2004), and neurodevelopment more broadly (Rapp, 1999, 2011). For autism, the historical roots of mother blame run particularly deep and, despite changing causal understandings of the diagnosis, continue to shape women's experiences (Nadesan, 2005). Doubly gendered concerns - involving the link between mothers and the wellbeing of sons have also become central to feminist analyses of autism, as the diagnosis currently affects boys four times more than girls (CDC, 2014). Numerous theories advanced to explain these ratios rely on binary definitions of sex without accounting for how social experiences of gender shape expectations of child development, behavior, and diagnosis. Blum (2015) argues that these rates must be considered with regard to the gendered norms that influence perceptions of 'good' and 'bad' children, as well as those that inform ideas of 'good' mothers. Cheslack-Postava and Jordan-Young (2012) suggest an integrated model of development that recognizes the relationships between sex/gender, biological pathways, observed and experienced autistic symptoms, and diagnostic practices. Their work emphasizes the biosocial effects of sex/gender on understandings of disability, while Blum points to the paradoxical weight that boys' disproportionate diagnoses place on mothers. My contribution to this literature is an analysis of how these longstanding views of maternal responsibility now extend into women's bodies.

\section{Shifting causal narratives and multiple autisms}

Once understood as rare, diagnoses of autism have increased significantly over the past several decades. Today, autism spectrum disorders are estimated to affect 1 in 56 children in the United States (CDC, 2014). While sociological and epidemiological analyses attribute much of the increased prevalence to rising awareness, diagnostic changes, deinstitutionalization, and school pressures, the idea of an 'autism epidemic' has nevertheless become a dominant characterization in popular claims about autism. Shifting understandings of autism point to the historical specificity of ways of knowing childhood difference and their relationship to controversies surrounding autism since it was first named by Leo Kanner in 1943 (Kanner, 1943; Silverman, 2011).

In the post-war years, mothers were explicitly seen as the cause of autism. Despite Kanner's initial assertion of the condition's inborn nature, autism came to be understood as 'a syndrome of ego damage resulting from unconscious parental rejection' (Kanner, 1943; in 
Silverman and Brosco, 2007: 393). Bettelheim (1967), alongside Kanner, popularized this theory, which became known as 'refrigerator mother' hypothesis. This suggested that it was bad mothering - lack of affection and cold, inappropriate and distant parenting - that forced children into their 'own world', causing the symptoms known as autism (Nadesan, 2005; Orsini, 2009).

Beginning with these psychogenic theories, women have been given substantial responsibility for autism. Sousa (2011) describes a transition in literature on mothering and autism from an idea of women as 'refrigerator mothers' to that of 'warrior-heroes', reflecting how the cultures of blame surrounding autism now emphasize women's nearly limitless responsibilities for care, rather than their culpability in causing autism. Today, the expectation is 'that mothers would devote limitless time, energy, and resources to their children's development' (Sousa, 2011: 220), an expectation that I argue now begins before birth and is incorporated into understandings of autism risk.

The dominant 1950s—1960s idea that refrigerator mothers caused autism generated significant stigma and became a catalyst for parent advocacy, which dramatically shifted understandings of autism (Eyal et al., 2010; Park, 1967; Silverman, 2011). During this era, due largely to the work of scientist Bernard Rimland (1964) and the efforts of mothers of autistic children, including Clara Claiborne Park (1967), the diagnosis began to be interpreted as a neurological condition of biologic origin (Eyal, 2010; Eyal et al., 2010; Silverman, 2011; Silverman and Brosco, 2007). At the heart of the gene age, questions moved away from mothers to focus again on the inborn basis of autism, tracing autism's biological roots through family lineages.

Navon and Eyal (2016) point out that the move toward a hereditary model of autism was influenced by the science of the time and a clinical observation made earlier by Kanner and others that children resembled their parents. Rimland was the father of an autistic child and saw these early observations as evidence of autism's genetic roots. Based on his experiences as a scientist and father, Rimland argued against psychogenic models. In 1977, a landmark study reinforced his claims by showing a high concordance of autism among monozygotic twins (Folstein and Rutter, 1977). This study helped establish autism as the most heritable psychiatric condition at that time, ushering in a deluge of studies to identify the 'gene for' autism (Muhle et al., 2004; Rutter, 2000; Singh, 2015). To date, numerous studies have established that, while autism is highly heritable, there is no single or even small number of genes 'for' the condition. Rather, there may be several hundred genes that interact with other genes and environmental factors to influence autism risk (Abrahams and Geschwind, 2008; Barua and Junaid, 2015). A recent study found distinct genetic mutations in autistic biological siblings, further complicating any simple genetic explanation for the condition (Yuen et al., 2015). By one estimation, identified genes or gene combinations (including gene mutations, deletions, copy number variations (CNVs), de novo mutations, and other anomalies) account for approximately 20 percent of autism cases (Berg and Geschwind, 2012). A leading geneticist recently remarked that given the complexity of autism genetics, autism is 'a roll of the genetic dice ... [and] each child with autism is like a snowflake, one is unique from another' (Scherer in Fox, 2015). 
These findings are not entirely surprising given the genetic heterogeneity of many complex traits, the influence of looping (Hacking, 2006), and the technologies now used to sequence human genomes at scales not imagined when the first linkage studies were published. These social, medical, and scientific dimensions of autism have helped produce a more heterogeneous research and diagnostic population (Navon and Eyal, 2016). Many scientists now agree that what we understand as autism is better characterized and scientifically workable as autisms, with the plural signaling that the phenotypes captured under the autism spectrum may actually reflect hundreds of distinct biologies, rather than any single cause.

Since the early 2000s, hypotheses about the causes of autism have increasingly incorporated questions about the role that environmental factors may play in autism (Daniels, 2006; Engel and Daniels, 2011). The move toward studying environmental factors and gene-environment interactions in autism mirrors a larger shift in the life sciences that has become more pronounced since the completion of the major genetics projects, including the Human Genome Project, the HapMap program, and the 1000 Genomes Project. These projects revealed that not only were the genetics of common traits and diseases more complex than previously envisioned, they were also likely to involve an interplay of genetic, environmental, and timing factors that had received little research attention in previous eras.

In this post-genomic era, genetics are increasingly seen as both foundational to and simultaneously incomplete in explaining the causes of complex conditions (Lappé and Landecker, 2015b; Meloni, 2014). New approaches in autism science are building on genetic findings in an effort to identify 'non-genetic' risk factors. These studies have been supported by CDC and the National Institutes of Environmental Health Sciences (NIEHS) initiatives that began to emphasize the importance of studying environmental factors in the early $2000 \mathrm{~s}$ (Baby Siblings Research Consortium [BSRC], 2009, 2011; Daniels, 2006; Engel and Daniels, 2011; Institute of Medicine [IOM], 2011). These efforts were influenced by public concerns over rising rates of autism and the lack of answers provided by genetics alone (Lawler, 2005, 2008). The studies funded by these initiatives established interdisciplinary teams comprised of genetic and environmental epidemiologists, toxicologists, endocrinologists, neurobiologists, and clinicians, who began a concerted effort to identify environmental contributions to autism. While research exploring environmental risks continues to be allocated a fraction of the funding available for genetic studies, several major investigations have built on early proof-of-principle findings to show that in utero exposures and parental effects may influence a child's risk of autism (cf. Chess, 1971).

A steady tide of findings from epidemiological and laboratory studies now suggests that air pollution, gestational diabetes, folic acid, placental health, maternal autoantibodies during pregnancy, and other factors may increase or decrease offspring autism risk (Braunschweig et al., 2008; Dietert et al., 2011; Eskenazi et al., 2007; Hertz-Picciotto et al., 2008;

Krakowiak et al., 2012; Zerbo et al., 2012). There has also been an increasing number of studies exploring the epigenetic mechanisms for autism (cf. LaSalle, 2013; Mbadiwe and Millis, 2013; Miyake et al., 2012). While published research suggests that environmental factors on the whole have a small effect on autism risk and some studies have yet to be replicated, the prominence of these publications in the news and in parents' conversations 
suggests that when it comes to environmental risks, it is their potential effects in and through the maternal body that have become central in ongoing questions about the causes of autism.

\section{From the womb to the maternal body as environment}

In July of 2011, newspapers and broadcasts were abuzz with reports about the largest twin study to explore genetic and environmental contributions to autism (Hallmayer et al., 2011). The study provided an empirical anchor to the shift toward environmental and geneenvironmental interaction research that had been gaining attention since the early 2000s. While twin studies had been central in establishing autism as a highly heritable condition in the late 1970s, it was a twin study in 2011 that suggested that genetic heritability for the condition had been overestimated. According to Hallmayer and colleagues (2011), it was 'the environment' that played a key role in autism.

Published in The Archives of General Psychiatry (now JAMA Psychiatry), 'Genetic heritability and shared environmental factors among twin pairs with autism' compared monozygotic and dizygotic twin pairs in which at least one twin had autism. Findings indicated a higher concordance among dizygotic twins than monozygotic twins, suggesting that 'shared environment' contributed more to autism risk than did genetics. Based on their findings, the authors concluded that twins' shared environment accounted for more than half of their risk for autism, while genetics accounted for less than half (Hallmayer et al., 2011).

Some in the popular press heralded the findings as a 'paradigm shift' in autism science (Kinnaman, 2011). Headlines across numerous news outlets, prominent autism websites, and science blogs pitted genes and environments against one another in headlines including 'Study debunks autism as a primarily genetic disorder', 'Environment blamed for autism', and 'Autism study: Environment matters even more than genetics' (Bole, 2011; Saey, 2011; Weintraub, 2011). Thomas Insel (2012), then Director of the National Institute of Mental Health, one of the leading federal funding agencies for autism science, argued that findings from this and other genetic studies should be viewed as evidence of the importance of studying both environmental factors and genetics in attempts to understand autism.

In terms of the specific environmental factors of interest, however, Hallmayer et al.'s own conclusions more clearly articulated what period - but not necessarily what causes - might matter most in assessments of environmental risk. Emphasizing early development, they stated,

Because the prenatal environment and early postnatal environment are shared between twin individuals, we hypothesize that at least some of the environmental factors impacting susceptibility to autism exert their effect during this critical period of life. (Hallmayer et al., 2011: 1095, emphasis added)

This temporal positioning of environmental importance has become central in ongoing efforts to identify risk factors for autism. A study by Croen et al. (2011) published alongside the Hallmayer study further emphasized the influence of this 'critical period of life' (Hallmayer et al., 2011: 1095). These authors found that maternal antidepressant use during the first trimester slightly increased the child's risk of having an autism spectrum disorder 
(Croen et al., 2011). These two studies and a comment accompanying the articles titled, 'Is autism, at least in part, a disorder of fetal programming?' (Szatmari, 2011), reflected that when it came to autism and the environment, it was the womb that had emerged as an environment of consequence in its own right.

'The womb as environment' was the title of Autism Speaks' science blog reporting on these 2011 publications (Lajonchere, 2011). This framing, and the collective conclusions drawn from the studies mentioned above, did the work of positioning the maternal body as a consequential site in the development of childhood autism. The commentary accompanying the articles further emphasized the maternal-fetal environment when it hypothesized that fetal programming might be at play in autism. Szatmari (2011, emphasis added) stated,

perhaps ASD can be considered, at least in part, a disorder of fetal programming (p. 1092). There is in fact evidence that certain risk factors that affect the maternal fetal environment may place the fetus at increased risk for ASD.

He went on, advocating studies that would advance research on autism and environmental factors:

Clearly a renewed effort needs to be undertaken. ... Many potential risk factors have been and need to be investigated, including parental age, maternal genotype, maternal-fetal immunoreactivity, in vitro fertilization, maternal ingestion of drugs, toxic chemicals in the environment during pregnancy, and maternal illnesses during pregnancy such as maternal diabetes or infections.

The call for additional research emphasized the importance of studying many environmental factors, especially as they become risks for children in and through the maternal body.

Recently, questions about environmental risks for autism have been expanded to include the potentially lasting influences that both men's and women's life experiences may have for their children's development (Barua and Junaid, 2015; Waggoner, 2013). Yet the particular emphasis on the maternal-fetal environment suggests that the broad focus of research on autism and the environment is overwhelmingly negotiated through the maternal body. A nuanced analysis of this science suggests a subtle but important continuum between risk factors imagined at the level of individual biology and those envisioned as the result of societal conditions. Both, nevertheless, position the maternal body as an environment of consequence for the future. Below I analyze two specific examples to illustrate how environmental risks are imagined and constructed in relation to the maternal body.

\section{The self-defensive body}

The New York Times opinion piece that inspired the illustration at the beginning of this article clearly reflects the stakes of positioning women's bodies as central in questions about autism's causes. In that piece, science journalist Velasquez-Manoff (2012) argues that autism is 'evidence of an abnormal, continuing biological process' that begins during fetal development. He describes a controversial area of autism science that has received growing attention in recent years: research on autism and the immune system (Velasquez-Manoff, 2012; cf. Underwood, 2013). 
Focusing on maternal immune dysregulation, Velasquez-Manoff (2012, emphasis added) states that, 'autism results from collateral damage. It's an unintended consequence of selfdefense during pregnancy'. He describes research positing that some forms of autism are the result of a maternal body that has gone awry, producing what he characterizes as an inhospitable environment for typical fetal brain development during pregnancy. The process he describes constructs autism as the result of conflict between the developing fetus and its most immediate environment - the mother - as well as one of the conflict between the mother and her own biology. Media coverage of this research suggests that some women's bodies turn what was originally a functional immune response into a danger now laying in wait, threatening to cause autism in their future children. This has the unintended effect of characterizing some women as fit for pregnancy and others as zones of potential harm for their future children.

Scientists at the University of California, Davis, MIND Institute have been at the forefront of research on the relationship between the immune system and autism. In 2013, Braunschweig and colleagues identified what they call "Maternal Autoantibody-Related" or MAR autism (Braunschweig et al., 2013). Their study of nearly 400 women followed research with animal models, which led to the identification of maternal autoantibodies that were associated with an autism-like phenotype in offspring. These autoantibodies were later found in a smaller cohort of human mothers of autistic children. In their ongoing research with mothers and children, Braunschweig et al. looked for the presence of the previously identified autoantibodies in mothers of 'typically developing' children and those with autistic children. They found that ' $23 \%$ of mothers of children with autism carried autoantibodies compared with only $1 \%$ of mothers of typically developing children' (Braunschweig et al., 2013). Based on their previous research and the disproportionate presence of autoantibodies across the two groups, the researchers identified these maternal autoantibodies as a key factor influencing the development of autism in some children.

Based on these findings and research that showed the impact of the autoantibodies on fetal brain proteins that influence neural development, UC Davis scientists hypothesized that these 'anti-brain autoantibodies' travel through the placenta, breech the blood-brain barrier in the developing fetus during formative periods of neurodevelopment, and affect critical proteins that influence the child's risk of autism. These same autoantibodies are blocked from affecting the maternal brain due to the fully developed blood-brain barrier in adults (Braunschweig et al., 2008, 2013). Importantly, the environmental 'trigger' that initiates this immune response in women remains unknown, but may occur years before pregnancy. This has led scientists to focus on how the presence of autoantibodies in women may affect their developing fetuses. Researchers do not believe the autoantibodies have direct effects on the women who carry them.

While Velasquez-Manoff's New York Times piece describes a broader range of research on autism and the immune system, the implications of focusing on the maternal body are clear in the intervention he introduces. To prevent autism - a goal that many feel reflects a narrow and problematic orientation - Velasquez-Manoff (2012) describes 'an ecosystem restoration project' that would involve administering medication to women on behalf of their children. This idea evokes the image of the maternal body as an environment in need of repair due to a 
woman's own biology. While this approach is not yet a reality, the suggestion points to the social and ethical consequences that the maternal body as environment may have, not only for our thinking about autism but for maternal responsibilities more broadly. This vision of the maternal body as an ecosystem suggests how molecular understandings of the environment may influence experiences of mother blame by positioning women themselves as in need of treatment because of the risk they pose to future children. The consequences of this treatment paradigm are particularly relevant in the context of recent epigenetic research, which highlights the importance of the environment while often emphasizing biological interventions.

\section{Testing the mother, testing the child ${ }^{3}$}

While the 'ecosystem restoration project' that Velasquez-Manoff describes may or may not come to pass, a diagnostic test for MAR autism is actively being developed. Following the publication of their 2013 paper, UC Davis and Dr. Judy Van de Water began the process of developing and licensing a diagnostic test for MAR autism with Pediatric Bioscience (2016). This raised concerns among scientists and advocates who warned about the limitations of existing research in this area and its early relationship to vaccine concerns (Conis, 2014; Mnookin, 2011; Underwood, 2013). Despite these issues, in a video announcing their efforts Dr. Van de Water describes the test, its implications and next steps, stating, 'it's what we call a rule-in test ... so the specificity is high enough that we think that, if you have [the antibodies] you will very likely have a child with autism'. She went on to say,

the final piece is that eventually we are going to try to come up with a therapeutic, an intervention - a biologic intervention to be able to treat women who are positive, keep those antibodies from getting to the target, and potentially being able to have a typically developing child. (Van de Water, 2013, emphasis added)

In this quote, we see a similar logic to Velasquez-Manoff's 'ecosystem restoration project', one that emphasizes the maternal body as a self-defensive site that produces autism as a result of a woman's own biology. This way of materializing environmental risk positions some women as in need of intervention on behalf of their future children. While some may see this proposal, the development of the test, and the research as fringe science, the support of National Institutes of Health (NIH) funding, publication in peer-reviewed journals, and circulation of these studies in the media, suggest that this research may come to reinforce women's biological responsibility for child wellbeing, especially if such a test becomes commercially or medically available. ${ }^{4}$

The description for MAR autism provided by Pediatric Bioscience reinforces the internalization of responsibility advanced by the test's development, as well as the

\footnotetext{
${ }^{3}$ This is a reference to Rapp's Testing Women, Testing the Fetus (1999). I use this subtitle to suggest the potential parallels between prenatal genetic tests and those identifying maternal autoantibodies now associated with autism.

${ }^{4}$ This research and Velasquez-Manoff's op-ed have been highly criticized (Underwood, 2013). Velasquez-Manoff notes that writing his piece in the declarative style of an op-ed 'may have been unwise. Especially for autism' (http://www.moisesvm.com/2012/09/09/ response-to-autism-oped-smackdowns-and-faqs/). The criticism he received may also have been due to the passionate response that many declarative statements about autism elicit, the controversy surrounding autism and the immune system (Kaufman, 2010), or the social justice implications of framing autism as a problem in need of a biological or technological solution rather than a difference in need of understanding and support (Orsini, 2009; Silberman, 2015).
} 
molecularization of the environment and individualization of risk characteristic of the maternal body as environment in autism science. Their website states,

In MAR autism, an unknown environmental trigger causes certain women to produce a number of specific autoantibodies. If these women get pregnant, the autoantibodies will cross the placenta, where they are believed to interfere with the activity of a number of key proteins in the brain of the developing fetus that play a critical role in neurodevelopment. (Pediatric Bioscience, 2016)

The relevance of a woman's past experiences for her biological ability to cultivate good life during pregnancy is central in this description. While promotional accounts describe the test as an empowering tool for women who carry the autoantibodies, such a development contributes to an image of women's bodies as critical sites for the future of autism and to their personal decisions as pivotal in shaping those futures. ${ }^{5}$

\section{Our chemical selves}

A second image of the maternal body as environment provides a potentially less insular vision of environmental risk, despite its continued emphasis on the maternal body. A 2012 editorial suggests an alternative framing of the environment from that advanced in research on maternal immune dysregulation: Landrigan and colleagues (2012) cite a 'growing recognition of the exquisite sensitivity of the developing human brain to toxic chemicals' during early windows of development including embryonic and fetal life (p. 369). This sensitivity has been documented in numerous studies (cf. Miodovnik et al., 2011), and in their call to action on neurodevelopmental disabilities, these scientists advocate that additional research that more fully examines the effect of industrial chemicals on neurodevelopment.

Citing a pandemic of neurodevelopmental disabilities, including autism, attentiondeficit hyperactivity disorder (ADHD), and dyslexia, Grandjean and Landrigan (2014) argue that 'new, precautionary approaches that recognize the unique vulnerability of the developing brain are needed for testing and control of chemicals' (p. 368). Their call connects the prevention of early life exposures to government-level regulation, providing a link between rising autism rates, chemical policies, and the unique vulnerability of the fetal brain during critical windows of development. Here, the maternal body provides a vehicle through which autism is manifested in children, but the orientation of intervention is aimed beyond the body.

This focus raises an important distinction between the risks proposed in this agenda and those advanced by the MAR autism studies. These different loci of attention - within and beyond the body - draw attention to how responsibilities for autism may be experienced and interpreted as individual or collective based in part on the causal narratives advanced by

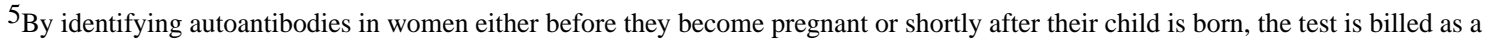
means of identifying autism before symptoms appear, allowing parents to begin behavioral interventions early or make alternative family planning decisions. The identification of autoantibodies associated with MAR autism is therefore seen as a resource for reproductive decision-making and an opportunity to enhance the efficacy of early interventions. This framing of the test on the Pediatric Bioscience (2016) website and in promotional videos overlooks the emphasis that such a test places on women's individual decisions. By positioning the test as a resource either before pregnancy or after birth, developers also sidestep the politics of abortion and its implications for neurodiversity.
} 
research. Grandjean and Landrigan (2014) go on to describe the challenges involved in measuring chemical toxicity, given the distinct effects that exposures may have for different individuals and over the life course:

The wide extent of human exposure to pollutants is now becoming apparent. ... However, recognition of causal associations could be difficult because exposures vary with time, more than one substance could have an effect, individual vulnerability varies, and other factors can bias epidemiological studies toward the null hypothesis, especially when the outcome might be unrecognized for several years, or even decades. (p. 8)

In light of the difficulties of measuring exposure levels, their toxicity, and associated outcomes, Landrigan et al. (2012) propose a research agenda that spans multiple scales, from experimental toxicology and neurobiology to epidemiology. Their call points to the lack of information about the effects of chemicals currently in circulation and uses the specter of rising rates of neurodevelopmental disorders to advance their case. They note that, 'a large number of the chemicals in widest use have not undergone even minimal assessment of potential toxicity, and only about $20 \%$ have been screened for potential toxicity during early development' (Landrigan and Goldman, 2011, in Landrigan et al., 2012: 368). The emphasis placed on regulation and testing positions responsibilities for these risks beyond individual bodies despite the authors' central use of in utero exposure as a rationale for increased research.

For scientists interested in the relationships between toxic substances and autism, the particular chemicals and timing of exposure are central, but so too are how those exposures are manifested. In this and other concerns about the effect of chemicals on fetal development and child health, women's exposures are differently meaningful depending on the chemicals, when before or during pregnancy exposure occurs, and their relationship to autism and other neurodevelopmental outcomes. This is because of the ability of some chemicals to pass through the placenta and accumulate in the fetus, a phenomenon that connects regulatory policies, women's exposures, and fetal development in intimate ways.

A committee opinion issued by the American College of Obstetricians and Gynecologists (ACOG) (2013) reinforces the pervasive but particular contours that influence how in utero exposures may influence child health. They state that 'chemicals in pregnant women can cross the placenta, and in some cases, such as with methyl mercury, can accumulate in the fetus, resulting in higher fetal exposure than maternal exposure' (ACOG, 2013). In calls for studies exploring the neurodevelopmental effects of chemicals, women's exposures matter, but when and how the maternal body receives, reacts, and processes these and whether they pass through the placenta influences the effect they may have on future children. The contingent qualities of these processes therefore position women's relationships to the external environment and the maternal- fetal environment as permeable and meaningful boundaries in the development of autism. These pathways may therefore provide an alternative orientation to interventions that target women's bodies alone, despite their continued emphasis on the maternal body as a critical site where environmental risks are manifested. 
Here, the maternal body as environment is a site of bioaccumulation, but one that occupies this position as a result of both regulatory decisions and individual exposures. This positions women as porous subjects who are urged to prevent individual exposures and advocate for regulation, based on the possibility that their children may be diagnosed with neurodevelopmental disabilities in the future. The continued emphasis on the effects of environmental risks in and through women's bodies positions autism risk simultaneously beyond the body and intimately embodied and transmitted through it.

\section{The body environmental}

In this article, I have traced how the regimes of perceptibility that accompany the postgenomic era have contributed to particular ways of visualizing and acting on the environment. These enable and reinforce the idea of autism as multiple, while positioning these multiplicities as a result of processes that unfold within some bodies more than others. By tracing the emergence of the maternal body as environment in autism science, I have highlighted how women as mothers and potential mothers remain central to questions about autism's causes, even as the contours of those questions become more biologically complex and temporally contingent. The examples of immune dysregulation and chemical exposures that I described suggest that risk is at once everywhere and intimately mediated through women's bodies. What we see is not the refrigerator mother of the past, but a maternal subject whose own biology and embodied experiences are intimately connected to the possibility of autism for her children.

In the examples above, environmental risks associated with autism are produced in and through the maternal body, but in ways that draw attention to a more diverse landscape of relations that may influence how we come to know both autism and maternal responsibilities. By drawing questions about environmental risk into the maternal body, contemporary research on autism and the environment emphasizes women's reproduction and forms of care as central to development, while also suggesting a stark contrast to the 'refrigerator mother' of the past. Where the refrigerator mother's cold and distant parenting was seen as the cause of her child's autism, the maternal body as environment describes a more molecular, individual, and internal orientation to questions about autism's causes. This way of visualizing and materializing autism risk draws the biomedical and social gaze toward women's bodies as reproductive objects and resources for population health, even before pregnancy.

In research on chemicals and toxins, scientists point to the importance of regulating these factors based on their potential impacts on fetal development. Their research positions women's bodies as consequential environments for autism due to the failure to regulate chemicals beyond the body. In the case of the maternal immune dysregulation and MAR autism, it is a woman's own immune system that produces the potential harm for her developing child, as she is positioned as an unknowing producer of the auto antibodies that may affect her developing fetus. The mechanism for MAR autism evokes a more internal orientation than research on chemicals and toxins, although the anti-brain autoantibodies under investigation may also occur as a response to external factors. These materializations of environmental risk emphasize women's bodies as sites for others, producing a new 
temporal and spatial politics of responsibility that is manifest in part through maternal biology. While women are central in both of these areas of autism research, their own health, surroundings, and embodied experiences are largely eclipsed by concerns for their children.

These examples therefore suggest a paradox: they draw attention to the maternal body without considering the effects that this orientation may have on women themselves; they emphasize the centrality of individual biology and common exposures for autism while providing women little control over either. By positioning the maternal body as an environment that either produces risk as a result of dysregulation in the case of autoantibodies, or receives, embodies and produces potential health or harm for the developing fetus in the case of chemical exposure, these areas of autism research reflect how women as mothers and potential mothers have again become central in questions about autism's causes in the post-genomic era.

\section{Conclusion}

From the emergence of research on autism and the environment to the maternal body as environment that has developed in its wake, autism science has become a vehicle for new approaches in the study of environmental risk factors. In the images and hypotheses above, I have discussed an increasingly diverse array of processes that may lead to autism. These hypothesized connections have positioned women's bodies as consequential sites of bioscientific attention. Through the molecularization of the environment, the individualization of risk, and the internalization of responsibility, the figure of the maternal body as environment in autism science suggests a new politics of autism, environmental risk, and maternal responsibility that is intimately tied to social anxieties about child development. The practices that result from these concerns help reinforce women's bodies as sites of social and medical surveillance. My analysis suggests that such a focus has at least three implications.

First, through the molecularization of the environment, women's experiences and exposures across the lifespan become uniquely valued in relationship to children's potential futures. This heightens social and medical scrutiny of women's bodies, but not necessarily the environments or social conditions that surround them. Through the molecularization of the environment, the maternal body itself becomes a consequential site for the development of autism. This move has the potential to obscure political and economic conditions that structure the unequal distribution of exposures in society and displace more holistic understandings of health. These causal narratives point to women's bodies as sites of contamination or dysregulation, emphasizing increased monitoring and diagnostic tests rather than structural or social change.

Second, through the individualization of risk, women's exposures before and during pregnancy, their age, and the lasting effects of their experiences on the body, produce increasingly complex reproductive equations that nevertheless remain focused on pregnancy, placing the burden of responsibility for child development on individual mothers. Furthermore, by aligning women's experiences and exposures with particular autism subtypes such as MAR autism, some areas of research may distribute risk factors and bodily 
relations in ways that shape new classifications of the diagnosis. This may lead to the identification of maternal risk subjects based in part on life history, the timing of their exposures, or the actions they take on behalf of others in response to these embodied risks.

Finally, the maternal body as environment points to an internalization of responsibility that extends the medicalization of childhood into women's bodies. This emphasis on women's bodies as sites where we manage social and scientific uncertainties surrounding child development extends longstanding views about maternal responsibility into earlier periods of life. Through this spatial and temporal move, questions about environmental risk are reinscribed onto women as reproductive subjects. This internalization of responsibility places biological processes at the center of larger questions about autism, and positions women's bodies and decisions as central in those processes. As these implications suggest, the maternal body as environment in autism science reflects a more molecular, individual, and internal orientation to questions about environmental risk and maternal responsibility one that calls for attention far beyond the body, not just within it.

\section{Acknowledgments}

Special thanks to Adele Clarke, Janet Shim, Chloe Silverman, Hannah Landecker, Rayna Rapp, Sarah Richardson, Katie Hasson, Jade Sasser, Rachel Washburn, Harvard University Mahindra Humanities Center Gender and Sexuality Seminar and the NYU Science Studies Colloquium, as well as the anonymous reviewers, for their helpful feedback on earlier versions of this article.

\section{Funding}

This research was supported by the UC Toxic Substances Research and Teaching Fellowship, UCSF Department of Social and Behavioral Sciences, UCLA Institute for Society and Genetics, and NHGRI Grant P50 HG007257-01.

\section{Biography}

Martine Lappé is a Postdoctoral Fellow in Columbia University's Center for Research on Ethical, Legal and Social Implications of Psychiatric, Neurologic, and Behavioral Genetics. Her research focuses on lived experiences and expert knowledge related to health, science, and medicine. She is completing a book titled Anticipating Autism: Science, Uncertainty, and Care in the Post-Genomic Era and pursuing a new project on the ethical and social implications of environmental epigenetics. Her scholarship appears in Social Studies of Science, New Genetics \& Society, BioSocieties, Journal of Medical Ethics, and in the books Achieving Justice in Genomic Translation: Rethinking the Pathway to Benefit and Advances in Medical Sociology: Genetics, Health and Society.

\section{References}

Abrahams BS, Geschwind DH. Advances in autism genetics: On the threshold of a new neurobiology. Nature Reviews Genetics. 2008; 9(5):341-356.

Adams V, Murphy M, Clarke AE. Anticipation: Technoscience, life, affect, temporality. Subjectivity. 2009; 28(1):246-265.

Almeling R, Waggoner MR. More and less than equal: How men factor in the reproductive equation. Gender \& Society. 2013; 27(6):821-842.

American College of Obstetricians and Gynecologists (ACOG). Committee opinion: Exposure to toxic environmental agents. 2013. Available at: http://www.acog.org/Resources-And-Publications/ 
Committee-Opinions/Committee-on-Health-Care-for-Underserved-Women/Exposure-to-ToxicEnvironmental-Agents (accessed on 21 January 2016)

Apple, RD. Perfect Motherhood: Science and Childrearing in America. New Brunswick, NJ: Rutgers University Press; 2006.

Armstrong, EM. Conceiving Risk, Bearing Responsibility : Fetal Alcohol Syndrome and the Diagnosis of Moral Disorder. Baltimore, MD: Johns Hopkins University Press; 2003.

Baby Siblings Research Consortium (BSRC). Baby Siblings Research Consortium, Research on high risk baby siblings, 2009 achievements. 2009. Available at: http://www.autismspeaks.org/science/ initiatives/high-risk-baby-sibs (accessed on 15 June 2012)

Baby Siblings Research Consortium (BSRC). Baby Siblings Research Consortium, Research on high risk baby siblings, 2011 achievements. 2011. Available at: http:/www.autismspeaks.org/science/ initiatives/high-risk-baby-sibs (accessed on 15 June 2012).

Barua S, Junaid MA. Lifestyle, pregnancy and epigenetic effects. Epigenomics. 2015; 7(1):85-102. [PubMed: 25687469]

Berg JM, Geschwind DH. Autism genetics: Searching for specificity and convergence. Genome Biology. 2012; 13(7):247-262. [PubMed: 22849751]

Bettelheim, B. The Empty Fortress: Infantile Autism and the Birth of the Self. New York: Free Press; 1967.

Blum, LM. At the Breast: Ideologies of Breastfeeding and Motherhood in the Contemporary United States. Boston, MA: Beacon Press; 1999.

Blum, LM. Raising Generation Rx: Mothering Kids with Invisible Disabilities in an Age of Inequality. New York: New York University Press; 2015.

Bole, K. Study debunks autism as a primarily genetic disorder. 2011. Available at: http:// www.ucsf.edu/news/2011/07/10153/study-debunks-autism-primarily-genetic-disorder (accessed on 6 January 2015)

Braunschweig D, Ashwood P, Krakowiak P, et al. Autism: Maternally derived antibodies specific for fetal brain proteins. NeuroToxicology. 2008; 29(2):226-231. [PubMed: 18078998]

Braunschweig D, Krakowiak P, Duncanson P, et al. Autism-specific maternal autoantibodies recognize critical proteins in developing brain. Translational Psychiatry. 2013; 3:e277. [PubMed: 23838888]

Casper, MJ. The Making of the Unborn Patient: A Social Anatomy of Fetal Surgery. New Brunswick, NJ: Rutgers University Press; 1998.

Centers for Disease Control and Prevention (CDC). Prevalence of autism spectrum disorder among children aged 8 years - Autism and developmental disabilities monitoring network, 11 sites, United States 2010. Surveillance Summaries. 2014; 63(SS02):1-21. Available at: http:// www.cdc.gov/mmwr/preview/mmwrhtml/ss6302a1.htm (accessed on 8 December 2015).

Centers for Disease Control and Prevention (CDC). Alcohol and pregnancy: Why take the risk?. Centers for Disease Control and Prevention vital signs; 2016. Available at: http://www.cdc.gov/ VitalSigns/Fasd/infographic.html\#graphic2 (accessed on 1 March 2016).

Charmaz, K. Constructing Grounded Theory: A Practical Guide through Qualitative Analysis. Thousand Oaks, CA: SAGE; 2014.

Cheslack-Postava K, Jordan-Young RM. Autism spectrum disorders: Toward a gendered embodiment model. Social Science \& Medicine. 2012; 74(11):1667-1674. [PubMed: 21803468]

Chess S. Autism in children with congenital rubella. Journal of Autism and Childhood Schizophrenia. 1971; 1(1):33-47. [PubMed: 5172438]

Clarke, AE. Situational Analysis: Grounded Theory after the Postmodern Turn. London: SAGE; 2005.

Conis, E. Vaccine Nation: America's Changing Relationship with Immunization. Chicago, IL: University of Chicago Press; 2014.

Croen LA, Grether JK, Yoshida CK, Odouli R, Hendrick V. Antidepressant use during pregnancy and childhood autism spectrum disorders. Archive of General Psychiatry. 2011; 68(11):1104-1112.

Daniels JL. Autism and the environment. Environmental Health Perspectives. 2006; 114(7):A396. [PubMed: 16835036] 
Davis, E. Illustration for 'An immune disorder at the root of autism'. The New York Times. 2012. Available at: http://www.nytimes.com/2012/08/26/opinion/sunday/immune-disorders-andautism.html?pagewanted=all\&; _r=0 (accessed on 7 January 2015).

Dietert RR, Dietert JM, Dewitt JC. Environmental risk factors for autism. Emerging Health Threats Journal. 2011; 4:7111. [PubMed: 24149029]

Engel SM, Daniels JL. On the complex relationship between genes and environment in the etiology of autism. Epidemiology. 2011; 22(4):486-488. [PubMed: 21642774]

Eskenazi B, Marks AR, Bradman A, et al. Organophosphate pesticide exposure and neurodevelopment in young Mexican-American children. Environmental Health Perspectives. 2007; 115(5):792-798. [PubMed: 17520070]

Eyal G. How parents of autistic children became 'experts on their own children': Notes toward a sociology of expertise. Berkeley Journal of Sociology. 2010; 54:3-17.

Eyal, G., Hart, B., Onculer, E., Oren, N., Rossi, N. The Autism Matrix: The Social Origins of the Autism Epidemic. Cambridge: Policy Press; 2010.

Folstein S, Rutter M. Infantile autism: A genetic study of 21 twin pairs. Journal of Child Psychology and Psychiatry. 1977; 18(4):297-321. [PubMed: 562353]

Fox, M. 'Lighting striking twice': Autism genes randomly mutated, study finds. NBC News (Kids' Health). 2015 Jan 26. Available at: http://www.nbcnews.com/health/kids-health/lightning-strikingtwice-autism-genes-randomly-mutated-study-finds-n293971 (accessed on 21 January 2016).

Friese C. Realizing potential in translational medicine: The uncanny emergence of care as science. Current Anthropology. 2013; 54(s7):S129-S138.

Ginsburg F, Rapp R. The politics of reproduction. Annual Review of Anthropology. 1991; 20:311-343.

Grandjean P, Landrigan PJ. Neurobehavioral effects of developmental toxicity. The Lancet Neurology. 2014; 13(3):330-338. [PubMed: 24556010]

Hacking I. Making up people. London Review of Books. 2006; 28(16):23-26.

Hallmayer J, Cleveland S, Torres A, et al. Genetic heritability and shared environmental factors among twin pairs with autism. Archives of General Psychiatry. 2011; 68(11):1095-1102. [PubMed: 21727249]

Hays, S. The Cultural Contradictions of Motherhood. New Haven, CT: Yale University Press; 1996.

Heilker P. Autism, rhetoric, and whiteness. Disability Studies Quarterly. 2012; 32(4) Available at: http://dsq-sds.org/article/view/1756.

Hertz-Picciotto I, Park HY, Dostal M, Kocan A, Trnovec T, Sram R. Prenatal exposures to persistent and non-persistent organic compounds and effects on immune system development. Basic \& Clinical Pharmacology \& Toxicology. 2008; 102(2):146-154. [PubMed: 18226068]

Hollin GJ, Pilnick A. Infancy, autism, and the emergence of a socially disordered body. Social Science \& Medicine. 2015; 143:279-286. [PubMed: 25103344]

Insel, T. The new genetics of autism - Why environment matters. NIH Director's Blog. 2012. Available at: http://www.nimh.nih.gov/about/director/2012/the-new-genetics-of-autism-whyenvironment-matters.shtml (accessed on 19 February 2015).

Institute of Medicine (IOM). Autism and the Environment: Challenges and Opportunities for Research: Workshop Proceedings. 2011. Available at: http://www.nationalacademies.org/hmd/Reports/2007/ Autism-and-the-Environment-Challenges-and-Opportunities-for-Research-WorkshopProceedings.aspx (accessed on 25 July 2016).

Kanner L. Autistic disturbances of affective contact. Nervous Child. 1943; 2:217-250.

Kaufman SR. Regarding the rise in autism: Vaccine safety doubt, conditions of inquiry, and the shape of freedom. ETHOS. 2010; 38(1):8-32.

Kinnaman, A. Autism mostly caused by environmental factors, Stanford study finds. Palo Alto Patch. 2011 Jul 7. Available at: http://patch.com/california/paloalto/autism-mostly-caused-byenvironmental-factors-stanfor11d6b1d233 (accessed on 21 January 2016).

Krakowiak P, Walker CK, Bremer AA, et al. Maternal metabolic conditions and risk for autism and other neurodevelopmental disorders. Pediatrics. 2012; 129(5):e1121-e1128. [PubMed: 22492772]

Kukla R. The ethics and cultural politics of reproductive health warnings: A case study of California's Proposition 65. Health, Risk \& Society. 2010; 12(4):323-333. 
Lajonchere, C. The womb as environment. Autism speaks blog. 2011. Available at: http:// www.autismspeaks.org/science/science-news/womb-environment (accessed on 6 January 2015)

Landecker H, Panofsky A. From social structure to gene regulation, and back: A critical introduction to environmental epigenetics for sociology. Annual Review of Sociology. 2013; 39:333-357.

Landrigan PJ, Goldman LR. Children's vulnerability to toxic chemicals: A challenge and opportunity to strengthen health and environmental policy. Health Affairs. 2011; 30(5):842-850. [PubMed: 21543423]

Landrigan PJ, Lambertini L, Birnbaum LS. A research strategy to discover the environmental causes of autism and neurodevelopmental disabilities. Environmental Health Perspectives. 2012; 120(7):A258-A260. [PubMed: 22543002]

Landsman, GH. Reconstructing Motherhood and Disability in the Age of 'Perfect' Babies. New York: Routledge; 2009.

Lappé MD. Taking care: Anticipation, extraction and the politics of temporality in autism science. BioSocieties. 2014; 9(3):304-328.

Lappé MD, Landecker H. How the genome got a lifespan. New Genetics and Society. 2015a; 34(2): 152-176. [PubMed: 26213491]

Lappé, MD., Landecker, H. Sociology in an age of genomic instability: Copy number variation, somatic mosaicism, and the fallen genome. In: Perry, BL., editor. Advances in Medical Sociology: Genetics, Health, and Society. London: Emerald; 2015b. p. 157-187.

LaSalle JM. Epigenomic strategies at the interface of genetic and environmental risk factors for autism. Journal of Human Genetics. 2013; 58(7):396-401. [PubMed: 23677056]

Lawler CP. Autism and the environment? Environmental Health Perspectives. 2005; 113(6):A405.

Lawler CP. The 'environment' for autism research: Signs of improvement? Environmental Health Perspectives. 2008; 116(10):A416. [PubMed: 18941547]

Lee, PY. The three letter word missing from Zika virus warnings. Dame Magazine (Health). 2016 Feb 2. Available at: http://www.damemagazine.com/2016/02/03/three-letter-word-missing-zika-viruswarnings (accessed on 1 March 2016)

Leiter V. 'Nobody's just normal, you know': Social creation of developmental disability. Social Science \& Medicine. 2007; 65(8):1630-1641. [PubMed: 17655995]

Lippman A. The geneticization of health and illness: Implications for social practice. Endocrinologie. 1991; 29(1-2):85-90. [PubMed: 1803494]

Litt, JS. Medicalized Motherhood: Perspectives from the Lives of African-American and Jewish Women. New Brunswick, NJ: Rutgers University Press; 2000.

Mackendrick N. More work for mother: Chemical body burdens as a maternal responsibility. Gender \& Society. 2014; 28(5):705-728.

Malaspina D, Gilman C, Krantz TM. Paternal age and mental health of offspring. Fertility and Sterility. 2015; 103(6):1392-1396. [PubMed: 25956369]

Marcus, GE. Ethnography through Thick and Thin. Princeton, NJ: Princeton University Press; 1998.

MARBLES. Markers of autism risk in babies - learning early signs. 2016. Available at: http:// marbles.ucdavis.edu/ (accessed on 10 July 2016).

Mbadiwe T, Millis RM. Epigenetics and autism. Autism Research \& Treatment. 2013; 2013:1-9.

Meloni M. Biology without biologism: Social theory in a postgenomic age. Sociology. 2014; 48(4): 731-746.

Miodovnik A, Engel SM, Zhu C, et al. Endocrine disruptors and childhood social impairment. NeuroToxicology. 2011; 32(2):261-267. [PubMed: 21182865]

Miyake, K., Hirasawa, T., Koide, T., Kubota, T. Epigenetics in autism and other neurodevelopmental diseases. In: Ahmad, S., editor. Advances in Experimental Medicine and Biology. New York: Springer; 2012. p. 91-98.

Mnookin, S. The Panic Virus: The True Story Behind the Vaccine-Autism Controversy. New York: Simon \& Schuster; 2011.

Muhle R, Trentacoste SV, Rapin I. The genetics of autism. Pediatrics. 2004; 113(5):472-486.

Murphy, M. Sick Building Syndrome and the Problem of Uncertainty: Environmental Politics, Technoscience, and Women Workers. Durham, NC: Duke University Press; 2006. 
Murphy M. Distributed reproduction, chemical violence, and latency. The Scholar and Feminist Online. 2013; 11(3):1-2.

Murray, S. Representing Autism: Culture, Narrative, Fascination. Liverpool: Liverpool University Press; 2008.

Nadesan, MH. Constructing Autism: Unravelling the 'Truth' and Understanding the Social. New York: Routledge; 2005.

Nature. CRISPR: The good, the bad and the unknown. 2016. Available at: http://www.nature.com/ news/crispr-1.17547 (accessed on 1 March 2016).

Navon D. Genetic designation: How genetics can delineate new, phenotypically diffuse medical categories. Social Studies of Science. 2011; 41(2):203-226. [PubMed: 21998922]

Navon D, Eyal G. Looping genomes: Diagnostic change and the genetic makeup of the autism population. American Journal of Sociology. 2016; 121(5):1416-1471.

Orsini, M. Contesting the autistic subject: Biological citizenship and the autism/autistic movement. In: Murray, SJ., Holmes, D., editors. Critical Interventions in the Ethics of Healthcare: Challenging the Principle Authority in Bioethics. London: Ashgate; 2009. p. 115-130.

Park, CC. The Siege: A Family's Journey into the World of an Autistic Child. Boston, MA: Little, Brown and Company; 1967.

Pediatric Bioscience. The MAR autism test. 2016. Available at: http://www.pedbio.com/mar_test/ mar_test.html (accessed on 25 July 2016).

Rabin, RC. Breast-feeding is good for mothers, not just babies, studies suggest. The New York Times (Well Blog). 2015. Available at: http://well.blogs.nytimes.com/2015/11/23/breast-feed-ing-isgood-for-mothers-not-just-babies/?ref=health\&;_r=0 (accessed on 21 January 2015).

Radin J. Latent life: Concepts and practices of tissue preservation in the International Biological Program. Social Studies of Science. 2013; 43(4):484-508.

Rapp, R. Testing Women, Testing the Fetus: The Social Impact of Amniocentesis in America. New York: Routledge; 1999.

Rapp R. Chasing science: Children's brains, scientific technologies, family participation. Science, Technology \& Human Values. 2011; 36(5):662-684.

Reichenberg A, Gross R, Weiser M, et al. Advancing parental age and autism. Archives of General Psychiatry. 2006; 63(9):1026-1032. [PubMed: 16953005]

Richardson, SS. Maternal bodies in the postgenomic order: Gender and the explanatory landscape of epigenetics. In: Richardson, SS., Stevens, H., editors. Postgenomics: Perspectives on Biology after the Genome. Durham, NC: Duke University Press; 2015. p. 210-231.

Rimland, B. Infantile Autism: The Syndrome and Its Implication for a Neural Theory of Behavior. London: Prentice Hall; 1964.

Rose, N. The Politics of Life Itself: Biomedicine, Power, and Subjectivity in the Twenty-First Century. Princeton, NJ: Princeton University Press; 2007.

Rutter M. Genetic studies of autism: From the 1970s into the millennium. Journal of Abnormal Child Psychology. 2000; 28(1):3-14. [PubMed: 10772346]

Saey, TH. Environment blamed for autism: Controversial twin study challenges idea that genes determine autism risk. Science News. 2011. Available at: https://www.sciencenews.org/article/ environment-blamed-autism (accessed on 6 January 2015)

Shostak, S. Exposed Science: Genes, the Environment, and the Politics of Population Health. Berkeley, CA: University of California Press; 2013.

Shostak, S., Moinster, M. The missing piece of the puzzle? Measuring the environment in the postgenomic moment. In: Richardson, SS., Stevens, H., editors. Postgenomics: Perspectives on Biology after the Genome. Durham, NC: Duke University Press; 2015. p. 192-209.

Silberman, S. Neurotribes: The Legacy of Autism and the Future of Neurodiversity. New York: Avery; 2015.

Silverman, C. Understanding Autism: Parents, Doctors, and the History of a Disorder. Princeton, NJ: Princeton University Press; 2011.

Silverman C, Brosco JP. Understanding autism: Parents and pediatricians in historical perspective. Archives of Pediatrics \& Adolescent Medicine. 2007; 161(4):392-398. [PubMed: 17404137] 
Singh I. Doing their jobs: Mothering with Ritalin in a culture of mother-blame. Social Science \& Medicine. 2004; 59(6):1193-1205. [PubMed: 15210091]

Singh, JS. Multiple Autisms: Spectrums of Advocacy and Genomic Science. Minneapolis, MN: University of Minnesota Press; 2015.

Sousa AC. From refrigerator mothers to warrior-heroes: The cultural identity transformation of mothers raising children with intellectual disabilities. Symbolic Interaction. 2011; 34(2):220 243.

Szasz, A. Shopping Our Way to Safety: How We Changed from Protecting the Environment to Protecting Ourselves. Minneapolis, MN: University of Minnesota Press; 2007.

Szatmari P. Is autism, at least in part, a disorder of fetal programming? Archives of General Psychiatry. 2011; 68(11):1091-1092. [PubMed: 21730328]

Timmermans, S., Buchbinder, M. Saving Babies? The Consequences of Newborn Genetic Screening. Chicago, IL: University of Chicago Press; 2012.

Underwood E. Alarm over autism test. Science. 2013; 341(6151):1164-1167. [PubMed: 24030995]

Van de Water Interview. UCD research: Autism linked to moms. 2013. Available at: https:// www.youtube.com/watch?v=-vuLhUeFOtU (accessed on 10 July 2016).

Velasquez-Manoff, M. An immune disorder at the root of autism. The New York Times. 2012. Available at: http://www.nytimes.com/2012/08/26/opinion/sunday/immune-disorders-andautism.html?pagewanted=all\&; r $=0$ (accessed on 7 January 2015).

Verhoeff B. What is this thing called autism? A critical analysis of the tenacious search for autism's essence. BioSocieties. 2012; 7(4):410-432.

Waggoner MR. Motherhood preconceived: The emergence of the preconception health and health care initiative. Journal of Health Politics, Policy and Law. 2013; 38(2):345-371.

Waggoner MR. Cultivating the maternal future: Public health and the pre-pregnant self. Signs: Journal of Women in Culture and Society. 2015; 40(4):939-962.

Washburn R. Measuring personal chemical exposures through biomonitoring: The experience of research participants. Qualitative Health Research. 2014; 24(3):329-344. [PubMed: 24549408]

Weintraub, K. Autism study: Environment matters even more than genetics. 2011. Available at: http:// commonhealth57.rssing.com/browser.php?indx=6574117\&item=3 (accessed on 10 July 2016).

Wolf, J. Is Breast Best? Taking on the Breastfeeding Experts and the New High Stakes of Motherhood. New York: New York University Press; 2011.

Yuen R, Thiruvahindrapuram B, Merico D, et al. Whole-genome sequencing of quartet families with autism spectrum disorder. Nature Medicine. 2015; 21(2):185-191.

Zerbo O, Iosif A, Walker C, et al. Is maternal influenza or fever during pregnancy associated with autism or developmental delays? Results from the CHARGE (CHildhood Autism Risks from Genetics and Environment) Study. Journal of Autism and Developmental Disorders. 2012; 43(1): 25-33. 


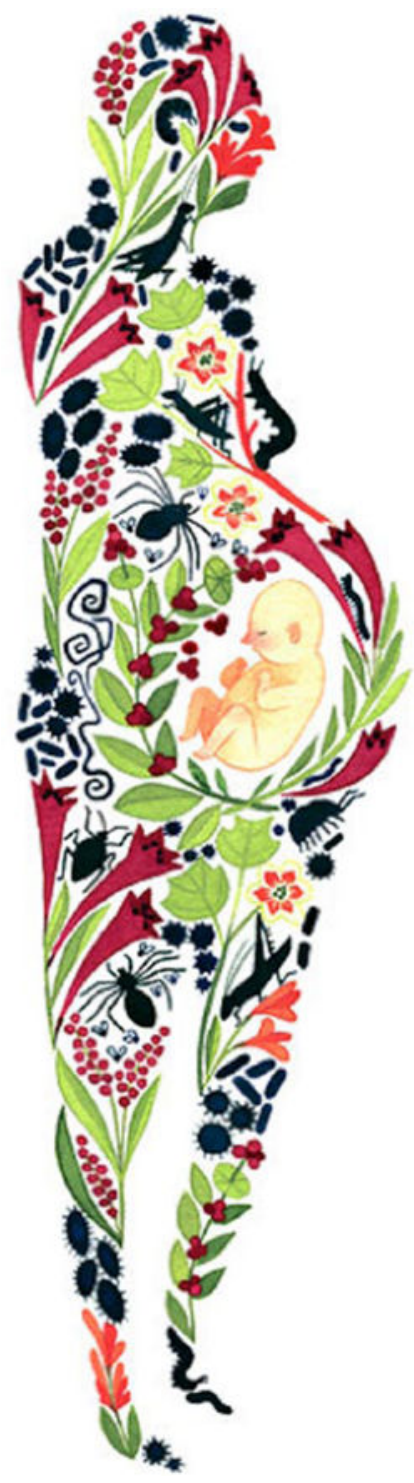

Figure 1.

Illustration by Eleanor Davis for The New York Times opinion, 'An immune disorder at the root of autism' (Velasquez-Manoff, 2012). 